\title{
Optimal Adaptive Control of Business Planning Processes Based on Network Economic and Mathematical Modeling
}

\author{
A. F. Shorikov ${ }^{1, a)}$ and E. V. Butsenko ${ }^{2, b)}$ \\ ${ }^{1}$ Ural Federal University, Ekaterinburg, Russia \\ ${ }^{2}$ Ural State University of Economics, Ekaterinburg, Russia

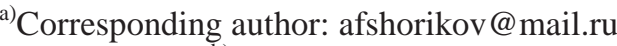 \\ b)evl@usue.ru
}

\begin{abstract}
The article discusses the problem of optimizing the adaptive control of business planning processes by an economic entity. The results of the work are based on a new method of network formalization and optimization of adaptive project management, using network economic and mathematical modeling and the principles of adaptive control. The paper describes a new optimization network economic and mathematical model. This model takes into account the possibilities of monitoring the states of the process under consideration and adaptive control of the implementation of a business project. Within the framework of the formed network model, a new method for solving the task of network formalization and optimization of adaptive control of business planning processes is proposed. When implementing the proposed method, a strategy for optimal adaptive control of business planning processes is formed. On its basis, the optimal time for the implementation of a business project and the optimal schedule for its implementation in general are calculated. The article describes the practical application of the proposed method for solving the considered optimization problem on a specific example of the implementation of business planning processes in the development of new dishes at a public catering enterprise. The results obtained in the work show the sufficient efficiency of the developed new method of formalization and optimization of adaptive control of business planning processes. Further development of this area of research can be associated with the development of an intelligent computer system for optimizing the adaptive control of business planning processes and the creation of appropriate tools to support the adoption of management decisions by business entities during their implementation.
\end{abstract}

\section{INTRODUCTION}

Modern conditions of economic development require the development and implementation of adaptive models for managing economic processes. For the majority of economic entities, one of the main problems is the lack of financial resources for the implementation of various projects. Business processes are carried out in a constantly changing environment. Therefore, the corresponding economic and mathematical models for optimizing business planning management must be adapted to the actual implementation of such processes. From the above it follows that the development and creation of an economic and mathematical model and a method for solving the task of optimizing adaptive control of business planning processes by an economic entity is a very urgent task.

Despite the significant theoretical and practical relevance in Russia and in developed foreign economies, the solution to the problem of formalizing and optimizing adaptive control of business planning processes has not been developed either in Russia or in other countries. From the available sources of scientific information, the authors are not aware of works on the mathematical formalization of the task of optimizing adaptive control within the framework of network models for managing business planning processes.

The purpose of this study is to create a network economic and mathematical model for optimizing adaptive control of business planning processes and develop a methodology for its practical implementation in instrumental systems for making managerial decisions by business entities.

Methodological basis of the study was the fundamental and applied scientific works of Russian and foreign authors in the field of economic and mathematical modeling, network planning and control, the mathematical theory of optimal and adaptive control [1-9].

Application of Mathematics in Technical and Natural Sciences AIP Conf. Proc. 2302, 060013-1-060013-15; https://doi.org/10.1063/5.0033584 Published by AIP Publishing. 978-0-7354-4036-4/\$30.00 
Results obtained in this work are based on the studies of the authors [10-12].

In this paper, a new method of network formalization and optimization of adaptive control of business planning processes is proposed, the essence of which can be briefly described as follows. Network economic and mathematical modeling [6,7] of a specific business project is carried out, based on the values of its parameters, a business plan and a calendar schedule for the implementation of business planning processes described by the corresponding work operations, as well as many acceptable positions (states) of business processes are formed plans corresponding to the permissible periods of control determined by the critical operations-operations, and the set of all admissible strategies for adaptive control of business planning processes [10]. At each step of the implementation of the control of business planning processes, which are determined by the work-operations of the corresponding critical path, in accordance with the rules for the formation of an optimal adaptive control strategy for business planning processes, monitoring (assessment) of the quality of the actual implementation of the work operations included in it is carried out on the basis of the prescribed duration of their execution and calendar data. Then, the deviation of the planned values of the parameters from their actual implementations is established, and if there is a deviation of the actual values of the parameters from their planned values, then the model parameters are adjusted to optimize it for the time required for the implementation of the business project as a whole. Next, a new critical path and a new calendar schedule for the next period of time are formed, and such a recurrent procedure for optimizing adaptive control of business planning processes is repeated until the implementation of the business project as a whole.

\section{METHOD OF NETWORK FORMALIZATION AND OPTIMIZATION ADAPTIVE CONTROL OF BUSINESS PLANNING PROCESSES}

The general method of network planning and control of business planning processes by an economic entity (without the possibility of adaptation) is given in $[11,12]$.

Below is a detailed description of the proposed new method of network formalization and optimization of adaptive control of business planning processes.

Let there be a specific business project for which there is an a priori specific technology that is implemented as part of the relevant business planning processes. It is assumed that all business planning processes as a whole can be described as a finite set of work-operations, ordered by time, taking into account the existing technological and technical and economic conditions. It is required to optimize (minimize) the implementation time of business planning processes in general, using the feedback control capabilities based on monitoring the implementation of the current state of their implementation.

Then the formation of the optimal adaptive control strategy for business planning processes for the business project under consideration can be described as the implementation of the following final sequence of actions.

1. Introduced: the initial array of work-operations $\boldsymbol{R}(0)=\left\{R_{1}(0), R_{2}(0), \ldots, R_{n_{0}}(0)\right\}=\boldsymbol{R}_{0}$, allowing to implement the business planning processes as a whole, consisting of work-operations $n_{0}\left(n_{0} \in \mathbf{N}\right.$; hereinafter, $\mathbf{N}$ the set of all natural numbers) with rules that determine their order in time and logical conditions, and the corresponding array of the duration of the execution of work-operations $\Delta(0)=\left\{\Delta_{1}(0), \Delta_{2}(0), \ldots, \Delta_{n_{0}}(0)\right\}=\Delta_{0}$; relies: the value of an integer time period $\tau:=0$; value of the natural parameter $s:=1$.

2. Then, for a set of work-operations $\boldsymbol{R}(\tau)=\left\{R_{1}(\tau), R_{2}(\tau), \ldots, R_{n_{\tau}}(\tau)\right\}=\boldsymbol{R}_{\tau}$, where $\tau \in\{\mathbf{N} \cup\{0\}\}$, given the given rules that determine the order of work-operations in time and logical conditions, and for an array of the duration of the work-operations $\Delta(\tau)=\left\{\Delta_{1}(\tau), \Delta_{2}(\tau), \ldots, \Delta_{n_{\tau}}(\tau)\right\}=\Delta_{\tau}$, in accordance with the rules for constructing a network model, the network modelingtask is solved - the formation of the optimal network model $\boldsymbol{W M}_{\tau}^{(e)}(\boldsymbol{R}(\tau)) \in \boldsymbol{W M}_{\tau}(\boldsymbol{R}(\tau))$ corresponding to it from the class of admissible network models $\boldsymbol{W} \boldsymbol{M}_{\tau}(\boldsymbol{R}(\tau))$ corresponding to set of work-operations $\boldsymbol{R}_{\tau}$.

3. For the formed network model $\boldsymbol{W M}_{\tau}^{(e)}(\boldsymbol{R}(\tau))$ corresponding to the set of work-operations $\boldsymbol{R}(\tau)=\left\{R_{1}(\tau), R_{2}(\tau), \ldots, R_{n_{\tau}}(\tau)\right\}=\boldsymbol{R}_{\tau}$, the task of constructing a critical path 
$\boldsymbol{R}^{(\kappa p .)}(\tau)=\left\{R_{1}^{(k p .)}\left(\tau ; \tau_{1}\right), R_{2}^{(k p .)}\left(\tau_{1} ; \tau_{2}\right), \ldots, R_{n_{\tau}^{(k p .)}}^{(\kappa p .)}\left(\tau_{n_{\tau}^{(k p .)}-1} ; \tau_{n_{\tau}^{(k p .)}}\right)\right\}=\boldsymbol{R}_{\tau}^{(k p .)} \subseteq \boldsymbol{R}_{\tau}$, consisting of a "continuous" sequence $n_{\tau}^{(\kappa p .)}$ of critical work-operations $\left(n_{\tau}^{(\kappa p .)} \in \mathbf{N}\right)$, is solved.

4. Based on the generated critical path $\boldsymbol{R}_{\tau}^{(\kappa p .)}=\left\{R_{1}^{(\kappa p .)}\left(\tau ; \tau_{1}\right), R_{2}^{(\kappa p .)}\left(\tau_{1} ; \tau_{2}\right), \ldots, R_{n_{\tau}^{(k p .)}}^{(\kappa p .)}\left(\tau_{n_{\tau}^{(k p .)}-1} ; \tau_{n_{\tau}^{(\kappa p .)}}\right)\right\}, \quad \mathrm{a}$ critical or optimal time $T_{\tau}^{(e)}$ for the implementation of the business project in question is formed as a whole $\left(T_{\tau}^{(e)} \in \mathbf{N}\right)$, and the following condition is fulfilled: $\sum_{k=0}^{n_{\tau}^{(\kappa p .)}-1}\left(\tau_{k+1}-\tau_{k}\right)=\tau_{n_{\tau}^{(\kappa p .)}}-\tau_{0}=\tau_{n_{\tau}^{(\kappa p .)}}-\tau=T_{\tau}^{(e)}\left(\tau_{0}=\tau\right)$.

5. Integer array of time periods $\boldsymbol{T}_{\tau}=\left\{\tau_{k}\right\}_{k \in 0, n_{\tau}^{(\kappa p .)}}$ is formed corresponding to the events of the formed critical path $\boldsymbol{R}_{\tau}^{(\kappa p .)}=\left\{R_{1}^{(\kappa p .)}\left(\tau ; \tau_{1}\right), R_{2}^{(\kappa p .)}\left(\tau_{1} ; \tau_{2}\right), \ldots, R_{n_{\tau}^{(\kappa p .)}}^{(\kappa p .)}\left(\tau_{n_{\tau}^{(k p .)}-1} ; \tau_{n_{\tau}^{(k p .)}}\right)\right\}$, where $\tau_{0}=\tau$, determining the least early start dates of all operations leaving the corresponding event, and the latest completion dates of all operations included in the corresponding event, and together with the critical time $T_{\tau}^{(e)}$ they are stored (here and further, for $n \in \mathbf{N}$, integer array $\overline{1, n}=\{1,2, \ldots, n\})$.

6. For the formed network model $\boldsymbol{W M}_{\tau}^{(e)}(\boldsymbol{R}(\tau))$, on the basis of the found critical path $\boldsymbol{R}_{\tau}^{(\kappa p .)}=\left\{R_{1}^{(\kappa p .)}\left(\tau ; \tau_{1}\right), R_{2}^{(\kappa p .)}\left(\tau_{1} ; \tau_{2}\right), \ldots, R_{n_{\tau}^{(\kappa p .)}}^{(\kappa p .)}\left(\tau_{n_{\tau}^{(\kappa p .)}-1} ; \tau_{n_{\tau}^{(k p .)}}\right)\right\}$ and the available source data, the task of scheduling is solved - the formation of the optimal schedule $\boldsymbol{T G}_{\tau}^{(e)}(\boldsymbol{R}(\tau))$ - a description of the time frame for the execution of all work operations $\boldsymbol{R}(\tau)=\left\{R_{1}(\tau), R_{2}(\tau), \ldots, R_{n_{\tau}}(\tau)\right\}=\boldsymbol{R}_{\tau}$, in the form of a Gantt chart, a threedimensional chart or in the form of a data table [11].

7. As a result of solving the scheduling task for each work-operation $R_{k}(\tau) \in \boldsymbol{R}_{\tau}=\left\{R_{1}(\tau), R_{2}(\tau), \ldots, R_{n_{\tau}}(\tau)\right\}$, $k \in \overline{1, n_{\tau}}$, a pair of time periods $S_{k}^{(b f)}=\left(T_{k}^{(b)}(\tau), T_{k}^{(f)}(\tau)\right)$ is determined, where $T_{k}^{(b)}(\tau)<T_{\tau}^{(e)}$ is the least early allowable deadline for the performance of the $k$ th work-operation, and $T_{k}^{(f)}(\tau) \leq T_{\tau}^{(e)}$ is the latest acceptable deadline for the performance of the $k$ th work-operation.

8. For a period of time $\tau_{1} \in \boldsymbol{T}_{\tau}$ we call a set $p\left(\tau_{1}\right)=\left\{\tau_{1}, \overline{\boldsymbol{R}}\left(\tau_{1} \mid \boldsymbol{R}_{0}, \boldsymbol{T}_{\tau}\right)\right\} \tau_{1}$-position for the considered process of managing business planning, where the set of work-operations $\overline{\boldsymbol{R}}\left(\tau_{1} \mid \boldsymbol{R}_{0}, \boldsymbol{T}_{\tau}\right)$ is determined by the following relation:

$$
\overline{\boldsymbol{R}}\left(\tau_{1} \mid \boldsymbol{R}_{0}, \boldsymbol{T}_{\tau}\right)=\left\{\bar{R}_{1}\left(\tau_{1}\right), \bar{R}_{2}\left(\tau_{1}\right), \ldots, \bar{R}_{m_{\tau_{1}}}\left(\tau_{1}\right)\right\}\left(m_{\tau_{1}} \in \mathbf{N}: m_{\tau_{1}} \leq n_{0}\right)
$$

$\forall k \in \overline{1, m_{\tau_{1}}}: \bar{R}_{k}\left(\tau_{1}\right)$-work-operation, which is included in the array of works-operations $\boldsymbol{R}(0)=\boldsymbol{R}_{0}$, i.e., $\bar{R}_{k}\left(\tau_{1}\right) \in$ $\in \boldsymbol{R}_{0}=\left\{R_{1}(0), R_{2}(0), \ldots, R_{n_{0}}(0)\right\}$ and such that it was realized partially or in full in a period of time $t: t=\tau<\tau_{1}$, i.e., no later than the beginning of a period of time $\tau_{1}$.

9. Let be $\boldsymbol{P}\left(\tau_{1}\right)=\left\{p_{k}\left(\tau_{1}\right)\right\}_{k \in \overline{1, r_{\tau_{1}}}}=\left\{\tau_{1}, \overline{\boldsymbol{R}}_{k}\left(\tau_{1} \mid \boldsymbol{R}_{0}, \boldsymbol{T}_{\tau}\right)\right\}_{k \in \overline{1, r_{\tau_{1}}}}$ a finite set of all admissible $\tau_{1}$-positions for the considered business planning control process $\left(r_{\tau_{1}} \in \mathbf{N}\right)$, corresponding to a period of time $\tau_{1} \in \boldsymbol{T}_{\tau}$ and such that the condition is satisfied: $\forall k \in \overline{1, r_{\tau_{1}}}, \exists l \in \overline{1, m_{\tau_{1}}^{(k)}}$ that the work-operation $\quad \bar{R}_{l}^{(k)}\left(\tau_{1}\right) \in \overline{\boldsymbol{R}}_{k}\left(\tau_{1} \mid \boldsymbol{R}_{0}, \boldsymbol{T}_{\tau}\right)==$ 
$\left\{\bar{R}_{1}^{(k)}\left(\tau_{1}\right), \bar{R}_{2}^{(k)}\left(\tau_{1}\right), \ldots, \bar{R}_{\tau_{1}}^{(k)}\left(\tau_{1}\right)\right\}\left(m_{\tau_{1}}^{(k)} \in \mathbf{N}: m_{\tau_{1}}^{(k)} \leq n_{0}\right)$ and one that was implemented partially or in full in a period of time $t: t=\tau<\tau_{1}$, i.e., to a period of time $\tau_{1}$.

10. We define for $\tau_{1} \in \boldsymbol{T}_{\tau}$ acceptable strategy for adaptive control of business planning processes $U_{a}$ as a mapping $U_{a}: \boldsymbol{P}\left(\tau_{1}\right) \rightarrow \mathbf{2}^{\boldsymbol{R}_{0}}$ that associates each $\tau_{1}$-position $p\left(\tau_{1}\right)=\left\{\tau_{1}, \overline{\boldsymbol{R}}\left(\tau_{1} \mid \boldsymbol{R}_{0}, \boldsymbol{T}_{\tau}\right)\right\} \in \boldsymbol{P}\left(\tau_{1}\right)$ with a set of work-operations $\boldsymbol{R}\left(\tau_{1}\right) \in \mathbf{2}^{\boldsymbol{R}_{0}}$, namely:

$$
U_{a}\left(p\left(\tau_{1}\right)\right)=\boldsymbol{R}\left(\tau_{1}\right),
$$

where $\boldsymbol{R}\left(\tau_{1}\right)=\left\{R_{1}\left(\tau_{1}\right), R_{2}\left(\tau_{1}\right), \ldots, R_{n_{\tau_{1}}}\left(\tau_{1}\right)\right\} \in \mathbf{2}^{\boldsymbol{R}_{0}}$ (hereinafter, for any set $M$, we denote by the symbol $\mathbf{2}^{M}$ the set of all its subsets; $n_{\tau_{1}} \in \mathbf{N}: n_{\tau_{1}} \leq n_{0}$ ).

We denote by the symbol $\boldsymbol{U}_{a}$ the set of all admissible strategies for adaptive control of business planning processes $U_{a}$.

11. For a period of time $\tau_{1} \in \boldsymbol{T}_{\tau}$, we call the set $p^{(e)}\left(\tau_{1}\right)=\left\{\tau_{1}, \boldsymbol{R}^{(e)}\left(\tau_{1} \mid \boldsymbol{R}_{0}, \boldsymbol{T}_{\tau}\right)\right\} \in \boldsymbol{P}\left(\tau_{1}\right)$ the optimal $\quad \tau_{1}$ - position for the process of adaptive control of business planning, where array work-operations $\boldsymbol{R}^{(e)}\left(\tau_{1} \mid \boldsymbol{R}_{0}, \boldsymbol{T}_{\tau}\right)$ are determined by the following relation:

$$
\boldsymbol{R}^{(e)}\left(\tau_{1} \mid \boldsymbol{R}_{0}, \boldsymbol{T}_{\tau}\right)=\left\{R_{1}^{(e)}\left(\tau_{1}\right), R_{2}^{(e)}\left(\tau_{1}\right), \ldots, R_{m_{\tau_{1}}}^{(e)}\left(\tau_{1}\right)\right\}\left(m_{\tau_{1}} \in \mathbf{N}: m_{\tau_{1}} \leq n_{0}\right)
$$

where $\forall k \in \overline{1, m_{\tau_{1}}}: R_{k}^{(e)}\left(\tau_{1}\right)$ - such and only such work that is included in the array of work-operations $\boldsymbol{R}(0)=\boldsymbol{R}_{0}$, i.e., $R_{k}^{(e)}\left(\tau_{1}\right) \in \boldsymbol{R}_{0}=\left\{R_{1}(0), R_{2}(0), \ldots, R_{n_{0}}(0)\right\}$ and which was realized in a period of time $t: t=\tau<\tau_{1}$ :, i.e., to a period of time $\tau_{1}$.

Let be

$$
\begin{gathered}
\hat{\boldsymbol{R}}^{(e)}\left(\tau_{1} \mid \boldsymbol{R}_{0}, \boldsymbol{T}_{\tau}\right)=\left\{\hat{R}_{1}^{(e)}\left(\tau_{1}\right), \hat{R}_{2}^{(e)}\left(\tau_{1}\right), \ldots, \hat{R}_{n_{0}-m_{\tau_{1}}}^{(e)}\left(\tau_{1}\right)\right\}, \\
\forall k \in \overline{1, n_{0}-m_{\tau_{1}}}:\left(\hat{R}_{k}^{(e)}\left(\tau_{1}\right) \in \boldsymbol{R}_{0}\right) \wedge\left(\hat{R}_{k}^{(e)}\left(\tau_{1}\right) \notin \boldsymbol{R}^{(e)}\left(\tau_{1} \mid \boldsymbol{R}_{0}, \boldsymbol{T}_{\tau}\right)\right) .
\end{gathered}
$$

Then the equality is true:

$$
\begin{gathered}
\boldsymbol{R}^{(e)}\left(\tau_{1} \mid \boldsymbol{R}_{0}, \boldsymbol{T}_{\tau}\right) \cup \hat{\boldsymbol{R}}^{(e)}\left(\tau_{1} \mid \boldsymbol{R}_{0}, \boldsymbol{T}_{\tau}\right)= \\
=\left\{R_{1}^{(e)}\left(\tau_{1}\right), R_{2}^{(e)}\left(\tau_{1}\right), \ldots, R_{m_{\tau_{1}}}^{(e)}\left(\tau_{1}\right)\right\} \bigcup\left\{\hat{R}_{1}^{(e)}\left(\tau_{1}\right), \hat{R}_{2}^{(e)}\left(\tau_{1}\right), \ldots, \hat{R}_{n_{0}-m_{\tau_{1}}}^{(e)}\left(\tau_{1}\right)\right\}=\boldsymbol{R}_{0} .
\end{gathered}
$$

12. We define a strategy for optimal adaptive control of business planning processes $U_{a}^{(e)} \in \boldsymbol{U}_{a}$ as follows:

1) for $\tau_{1}$-position $p^{(e)}\left(\tau_{1}\right)=\left\{\tau_{1}, \boldsymbol{R}^{(e)}\left(\tau_{1} \mid \boldsymbol{R}_{0}, \boldsymbol{T}_{\tau}\right)\right\} \in \boldsymbol{P}\left(\tau_{1}\right)$ let

$$
\begin{gathered}
U_{a}^{(e)}\left(p^{(e)}\left(\tau_{1}\right)\right)=\boldsymbol{R}^{(e)}\left(\tau_{1}\right)=\left\{\boldsymbol{R}_{0} \backslash \boldsymbol{R}^{(e)}\left(\tau_{1} \mid \boldsymbol{R}_{0}, \boldsymbol{T}_{\tau}\right)\right\}=\hat{\boldsymbol{R}}^{(e)}\left(\tau_{1} \mid \boldsymbol{R}_{0}, \boldsymbol{T}_{\tau}\right)= \\
=\left\{R_{1}(0), R_{2}(0), \ldots, R_{n_{0}}(0)\right\} \backslash\left\{R_{1}^{(e)}\left(\tau_{1}\right), R_{2}^{(e)}\left(\tau_{1}\right), \ldots, R_{m_{\tau_{1}}}^{(e)}\left(\tau_{1}\right)\right\}= \\
=\left\{R_{1}(0), R_{2}(0), \ldots, R_{n_{0}}(0)\right\} \backslash\left\{R_{1}^{(e)}(0), R_{2}^{(e)}(0), \ldots, R_{m_{\tau_{1}}}^{(e)}(0)\right\}= \\
=\left\{\hat{R}_{1}^{(e)}\left(\tau_{1}\right), \hat{R}_{2}^{(e)}\left(\tau_{1}\right), \ldots, \hat{R}_{n_{0}-m_{\tau_{1}}}^{(e)}\left(\tau_{1}\right)\right\}=\left\{\hat{R}_{1}^{(e)}\left(\tau_{1}\right), \hat{R}_{2}^{(e)}\left(\tau_{1}\right), \ldots, \hat{R}_{\tau_{\tau_{1}}}^{(e)}\left(\tau_{1}\right)\right\}=
\end{gathered}
$$




$$
=\left\{R_{1}\left(\tau_{1}\right), R_{2}\left(\tau_{1}\right), \ldots, R_{n_{\tau_{1}}}\left(\tau_{1}\right)\right\}=\boldsymbol{R}_{\tau_{1}},
$$

where $n_{\tau_{1}}=n_{0}-m_{\tau_{1}} ; \quad \boldsymbol{R}^{(e)}\left(\tau_{1} \mid \boldsymbol{R}_{0}, \boldsymbol{T}_{\tau}\right)=\left\{R_{1}^{(e)}\left(\tau_{1}\right), R_{2}^{(e)}\left(\tau_{1}\right), \ldots, R_{m_{\tau_{1}}}^{(e)}\left(\tau_{1}\right)\right\} \quad-\quad$ a $\quad$ set $\quad$ of $\quad$ work-operations corresponding to the $\tau_{1}$-position $p^{(e)}\left(\tau_{1}\right)$; if $\boldsymbol{R}^{(e)}\left(\tau_{1}\right)=\boldsymbol{R}_{\tau_{1}}=\varnothing$, then $s:=s+1 ; t_{s}:=\tau_{1} ; p_{a}^{(e)}\left(t_{s}\right):=p^{(e)}\left(\tau_{1}\right)$ $; \boldsymbol{T}_{a}^{(e)}=T_{\tau}^{(e)}$ and transition to paragraph 14; otherwise $-s:=s+1 ; t_{s}:=\tau_{1} ; p_{a}^{(e)}\left(t_{s}\right):=p^{(e)}\left(\tau_{1}\right)$; on the basis of a part of the data contained in the array $\Delta(\tau)=\left\{\Delta_{1}(\tau), \Delta_{2}(\tau), \ldots, \Delta_{n_{\tau}}(\tau)\right\}=\Delta_{\tau}$ and available real data on the implementation of the project, a new array of the duration of the execution of work-operations $\Delta\left(\tau_{1}\right)=\left\{\Delta_{1}\left(\tau_{1}\right)\right.$, $\left.\Delta_{2}\left(\tau_{1}\right), \ldots, \Delta_{n_{\tau_{1}}}\left(\tau_{1}\right)\right\}=\Delta_{\tau_{1}}$ corresponding to the time period $\tau_{1}$ is calculated corresponding to the array of operations $\boldsymbol{R}^{(e)}\left(\tau_{1}\right)=\left\{R_{1}\left(\tau_{1}\right), R_{2}\left(\tau_{1}\right), \ldots, R_{n_{\tau_{1}}}\left(\tau_{1}\right)\right\}=\boldsymbol{R}_{\tau_{1}} ;$ relies $\tau:=\tau_{1}$ and proceeds to paragraph 3;

2) for $\tau_{1}$-position $p\left(\tau_{1}\right)=\left\{\tau_{1}, \overline{\boldsymbol{R}}\left(\tau_{1} \mid \boldsymbol{R}_{0}, \boldsymbol{T}_{\tau}\right)\right\} \in\left\{\boldsymbol{P}\left(\tau_{1}\right) \backslash\left\{p^{(e)}\left(\tau_{1}\right)\right\}\right\}$, let

$$
\begin{gathered}
U_{a}^{(e)}\left(p\left(\tau_{1}\right)\right)=\boldsymbol{R}\left(\tau_{1}\right)=\breve{\boldsymbol{R}}\left(\tau_{1}\right) \bigcup\left\{\boldsymbol{R}_{0} \backslash \overline{\boldsymbol{R}}\left(\tau_{1} \mid \boldsymbol{R}_{0}, \boldsymbol{T}_{\tau}\right)\right\}=\hat{\boldsymbol{R}}\left(\tau_{1} \mid \boldsymbol{R}_{0}, \boldsymbol{T}_{\tau}\right)= \\
=\left\{\breve{R}_{1}\left(\tau_{1}\right), \breve{R}_{2}\left(\tau_{1}\right), \ldots, \breve{R}_{\tau_{\tau_{1}}}\left(\tau_{1}\right)\right\} \bigcup\left\{\left\{R_{1}(0), R_{2}(0), \ldots, R_{n_{0}}(0)\right\} \backslash\left\{\bar{R}_{1}\left(\tau_{1}\right), \bar{R}_{2}\left(\tau_{1}\right), \ldots, \bar{R}_{m_{\tau_{1}}}\left(\tau_{1}\right)\right\}\right\}= \\
=\left\{R_{1}\left(\tau_{1}\right), R_{2}\left(\tau_{1}\right), \ldots, R_{n_{0}-m_{\tau_{1}}+l_{\tau_{1}}}\left(\tau_{1}\right)\right\}=\left\{\hat{R}_{1}\left(\tau_{1}\right), \hat{R}_{2}\left(\tau_{1}\right), \ldots, \hat{R}_{n_{\tau_{1}}}\left(\tau_{1}\right)\right\}= \\
=\left\{R_{1}\left(\tau_{1}\right), R_{2}\left(\tau_{1}\right), \ldots, R_{n_{\tau_{1}}}\left(\tau_{1}\right)\right\}=\boldsymbol{R}_{\tau_{1}},
\end{gathered}
$$

where $\overline{\boldsymbol{R}}\left(\tau_{1} \mid \boldsymbol{R}_{0}, \boldsymbol{T}_{\tau}\right)=\left\{\bar{R}_{1}\left(\tau_{1}\right), \bar{R}_{2}\left(\tau_{1}\right), \ldots, \bar{R}_{m_{\tau_{1}}}\left(\tau_{1}\right)\right\}$ is the set of work-operations corresponding to the $\quad \tau_{1}$ -position, taking into account that $p\left(\tau_{1}\right) \neq p^{(e)}\left(\tau_{1}\right), \quad$ it $\quad$ is $\quad$ supposed: $\forall l \in \overline{1, l_{\tau_{1}}} \quad$ work-operation $\bar{R}_{k_{l}}\left(\tau_{1}\right)=\widetilde{R}_{l}\left(\tau_{1}\right) \cup \breve{R}_{l}\left(\tau_{1}\right) \in \overline{\boldsymbol{R}}\left(\tau_{1} \mid \boldsymbol{R}_{0}, \boldsymbol{T}_{\tau}\right)$, here $\widetilde{R}_{l}\left(\tau_{1}\right)$ is the part of the work-operation $\bar{R}_{k_{l}}\left(\tau_{1}\right)$ that has been completed by the time period $\tau_{1}$, and $\breve{R}_{l}\left(\tau_{1}\right)$ is the remaining part of the work-operation $\bar{R}_{k_{l}}\left(\tau_{1}\right)$ that has not yet been completed time period ( $k_{l} \in 1, n_{\tau_{1}}$ ), because, for example, there was a delay in its execution, $l_{\tau_{1}}$ is the number of work-operations for which there was a delay in their execution or only partial execution by the time period $\tau_{1}$ (by assumption, for each such work-operation there is only one delay in the time of its execution), $l_{\tau_{1}} \in \mathbf{N} ; n_{\tau_{1}}=$ $n_{0}-m_{\tau_{1}}+l_{\tau_{1}} ; \quad \breve{\boldsymbol{R}}\left(\tau_{1}\right)=\left\{\breve{R}_{1}\left(\tau_{1}\right), \breve{R}_{2}\left(\tau_{1}\right), \ldots, \breve{R}_{\tau_{\tau_{1}}}\left(\tau_{1}\right)\right\}=\breve{\boldsymbol{R}}_{\tau_{1}} ; \quad \boldsymbol{R}\left(\tau_{1}\right)=\left\{R_{1}\left(\tau_{1}\right), R_{2}\left(\tau_{1}\right)\right.$, $\left.\left.\ldots, R_{\tau_{\tau_{1}}}\left(\tau_{1}\right)\right\}=\boldsymbol{R}_{\tau_{1}} \neq \varnothing \ldots, R_{n_{\tau_{1}}}\left(\tau_{1}\right)\right\}=\boldsymbol{R}_{\tau_{1}} \neq \varnothing$ - a set of work-operations, also corresponding to $\tau_{1}$-position $p\left(\tau_{1}\right)$ and such that the condition $\forall k \in \overline{1, n_{\tau_{1}}}$ is fulfilled: $R_{k}\left(\tau_{1}\right) \in \boldsymbol{R}_{0}$ work-operation and one that can actually be realized in a period of time $t: t \geq \tau_{1}$, in particular $\forall l \in \overline{1, l_{\tau_{1}}}: \breve{R}_{l}\left(\tau_{1}\right) \in \boldsymbol{R}\left(\tau_{1}\right)$; based on the part of the data contained in the array $\Delta(\tau)=\left\{\Delta_{1}(\tau), \Delta_{2}(\tau), \ldots, \Delta_{n_{\tau}}(\tau)\right\}=\Delta_{\tau}$ and the real data on the implementation of the business project, for the generated array of work-operations $\boldsymbol{R}\left(\tau_{1}\right)=\left\{R_{1}\left(\tau_{1}\right), R_{2}\left(\tau_{1}\right), \ldots, R_{n_{\tau_{1}}}\left(\tau_{1}\right)\right\}=\boldsymbol{R}_{\tau_{1}}$, the 
corresponding array of the duration of the work-operations $\Delta\left(\tau_{1}\right)=\left\{\Delta_{1}\left(\tau_{1}\right), \Delta_{2}\left(\tau_{1}\right), \ldots, \Delta_{n_{1}}\left(\tau_{1}\right)\right\}=\Delta_{\tau_{1}}$ is calculated, taking into account the presence of a delay in the execution or partial execution of some work-operations, and corresponding to the time period $\tau_{1}$; relies on: $s:=s+1 ; t_{s}:=\tau_{1} ; p_{a}^{(e)}\left(t_{s}\right):=p\left(\tau_{1}\right) ; \tau:=\tau_{1}$ and the transition to paragraph 3 of this method.

13. The output of the considered process of optimizing adaptive control of business planning processes by implementing the strategy $U_{a}^{(e)} \in \boldsymbol{U}_{a}$ is a data set: $\boldsymbol{R}_{a}^{(e)}=\boldsymbol{R}(0)=\left\{R_{1}(0), R_{2}(0), \ldots, R_{n_{0}}(0)\right\}=\boldsymbol{R}_{0}-$ the initial set of work-operations; $\boldsymbol{W M}_{a}^{(e)}=\boldsymbol{W M}_{0}^{(e)}(\boldsymbol{R}(0))$ - optimal network model; $p_{a}^{(e)}\left(t_{k}\right)$ - a set of $t_{k}$-positionsk $\in \overline{1, s}$ corresponding to the implementation of the strategy of optimal adaptive control of business planning processes $U_{a}^{(e)}$ $\boldsymbol{T}_{a}^{(e)}=T_{\tau}^{(e)}$ - optimal time for the implementation of the business project as a whole, corresponding to the implementation of the strategy for optimal adaptive control of business planning processes $U_{a}^{(e)}$.

14. The results obtained are displayed in a form convenient for an economic entity (a decision maker) that implements optimization of adaptive control of business planning processes.

\section{APPLICATION METHOD OF NETWORK ECONOMIC AND MATHEMATICAL MODELING FOR OPTIMIZATION ADAPTIVE CONTROL OF BUSINESS PLANNING}

Consider the application of the proposed new method of network formalization and optimization of adaptive control of business planning processes by the example of a business project in the field of public catering. The catering company is going to introduce new desserts into its menu, which requires justification of the effectiveness of future costs for their production and sale.

Initial data for all necessary work-operations during the implementation of the business project under consideration are presented in Table 1, where for each work-operation the duration of its execution and previous work are indicated.

TABLE 1. Initial data for a business project

\begin{tabular}{llcc}
\hline Work & \multicolumn{1}{c}{ Content of work } & $\begin{array}{c}\text { Duration of } \\
\text { work, weeks }\end{array}$ & $\begin{array}{c}\text { Previous } \\
\text { work }\end{array}$ \\
\hline$R_{1}(0)$ & Drawing up a list of products for introduction to assortment, monitoring of market & $\Delta_{1}(0)=1$ & - \\
$R_{2}(0)$ & prices for product & $\Delta_{2}(0)=1$ & $R_{1}(0)$ \\
$R_{3}(0)$ & Cost calculation & $\Delta_{3}(0)=1$ & $R_{2}(0)$ \\
$R_{4}(0)$ & Calculation of daily / weekly production rates & $\Delta_{4}(0)=2$ & $R_{2}(0)$ \\
$R_{5}(0)$ & Development of a product promotion program & $\Delta_{5}(0)=1$ & $R_{1}(0)$ \\
$R_{6}(0)$ & Retail price determination & $\Delta_{6}(0)=1$ & $R_{3}(0), R_{5}(0)$ \\
$R_{7}(0)$ & Preparation of presentation materials & $\Delta_{7}(0)=1$ & $R_{5}(0)$ \\
$R_{8}(0)$ & Definition of conditions and terms of storage & $\Delta_{8}(0)=1$ & $R_{2}(0)$ \\
$R_{9}(0)$ & Assessment of quality and safety indicators & $\Delta_{9}(0)=1$ & $R_{2}(0), R_{8}(0)$ \\
$R_{10}(0)$ & Presentation. Tasting. Familiarization of personnel with the properties of dessert & $\Delta_{10}(0)=1$ & $R_{7}(0)$ \\
\hline
\end{tabular}

Then, based on the available source data and conditions, a network economic-mathematical model of the implementation of business planning processes is formed in the form of a network diagram, which is shown in Figure 1. The initial event in this network is the event number 1, the final event is the event number 9. Symbols indicate fictitious work that does not require time and resources for their implementation.

In accordance with the proposed and described above new method of network formalization and optimization of adaptive control of business planning processes, a methodology has been developed for optimizing adaptive control of business planning processes that implement the initial business project at the optimal (minimum) time.

At the first stage, auxiliary parameters $\tau:=0, s:=0$ and on the basis of the initial data on the business planning processes under consideration, as well as the rules of network economic and mathematical modeling [6,7], the 
corresponding network model for the implementation of business planning processes is formed $\boldsymbol{W M}_{\tau}^{(e)}(\boldsymbol{R}(\tau))=$ $\boldsymbol{W M}_{0}^{(e)}(\boldsymbol{R}(0)) \in \boldsymbol{W M}_{0}(\boldsymbol{R}(0))$, where $\boldsymbol{W M}_{0}(\boldsymbol{R}(0))$ is the set of all valid network models, in the form of a network diagram, which is shown in Figure 1 and corresponds to an array of work-operations $\boldsymbol{R}(\tau)=\left\{R_{1}(\tau), R_{2}(\tau), \ldots\right.$, $\left.R_{n_{\tau}}(\tau)\right\}=\boldsymbol{R}_{\tau}=R(0)=\left\{R_{1}(0), R_{2}(0), \ldots, R_{10}(0)\right\}=\boldsymbol{R}_{0}$, as well as an array of the duration of the execution of work-operations $\Delta(\tau)=\left\{\Delta_{1}(\tau), \Delta_{2}(\tau), \ldots, \Delta_{n_{\tau}}(\tau)\right\}=\Delta_{\tau}=\Delta(0)==\left\{\Delta_{1}(0), \Delta_{2}(0), \ldots, \Delta_{10}(0)\right\}=\Delta_{0}$.

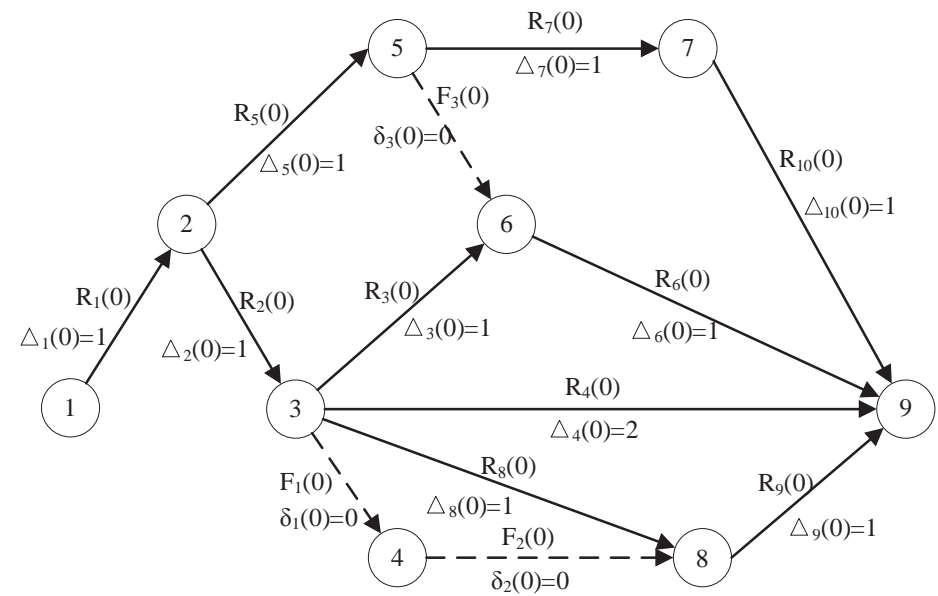

FIGURE 1. Network model for implementing business planning $(\tau=0)$

At the second stage, based on the initial data, including - the initial array of work-operations $\boldsymbol{R}(\tau)=\left\{R_{1}(\tau), R_{2}(\tau), \ldots, R_{n_{\tau}}(\tau)\right\}=\boldsymbol{R}_{\tau}=R(0)=\left\{R_{1}(0), R_{2}(0), \ldots, R_{10}(0)\right\}=\boldsymbol{R}_{0}$, the corresponding array of the duration of the work-operations $\Delta(\tau)=\left\{\Delta_{1}(\tau), \Delta_{2}(\tau), \ldots, \Delta_{n_{\tau}}(\tau)\right\}=\Delta_{\tau}=\Delta(0)=\left\{\Delta_{1}(0), \Delta_{2}(0), \ldots, \Delta_{10}(0)\right\}=\Delta_{0}$ as well as the generated network model for implementing business planning processes, it is necessary to optimize the network model by the time parameter - find the critical path, the critical time and create an appropriate calendar schedule for the implementation of business planning processes in general, i.e., solve the task of scheduling [6,7].

Formulas for calculating the time parameters of the events of the formed network model are described, for example, in [6,7]. For this network model that corresponds to the business planning processes, there are four critical paths, which are presented in Figure 2 and are highlighted in gray and in bold, with each of them having a duration of 4 weeks. All work-operations are critical. To perform further actions, any of these critical paths is selected, and specifically, we select the path that consists of a set of work-operations: $\left\{R_{1}(\tau), R_{2}(\tau), R_{3}(\tau), R_{6}(\tau)\right\}==$ $\left\{R_{1}(0), R_{2}(0), R_{3}(0), R_{6}(0)\right\} . \quad$ As $\quad$ a $\quad$ result, $\quad$ a $\quad$ critical $\quad$ path $\boldsymbol{R}^{(\kappa p .)}(\tau)=\left\{R_{1}^{(\kappa p .)}\left(\tau ; \tau_{1}\right), R_{2}^{(\kappa p .)}\left(\tau_{1} ; \tau_{2}\right), \ldots\right.$, $\left.R_{n_{\tau}^{(\kappa p .)}}^{(\kappa p .)}\left(\tau_{n_{\tau}^{(\kappa p .)}-1} ; \tau_{n_{\tau}^{(\kappa p .)}}\right)\right\}=\boldsymbol{R}_{\tau}^{(\kappa p .)}=\left\{R_{1}^{(\kappa p .)}(0 ; 1), R_{2}^{(\kappa p .)}(1 ; 2), R_{3}^{(\kappa p .)}(2 ; 3), R_{4}^{(k p .)}(3 ; 4)\right\}=\boldsymbol{R}^{(\kappa p .)}(0)=\quad \boldsymbol{R}_{0}^{(\kappa p .)} \quad$ is formed, where $n_{\tau}^{(\kappa p .)}=4$. The duration of the implementation of the generated critical path $\boldsymbol{R}_{\tau}^{(\kappa p .)}=\boldsymbol{R}_{0}^{(\kappa p .)}$ determines the critical time $T_{\tau}^{(e)}=T_{0}^{(e)}=4$, i.e., the optimal (minimum) time required to complete all workoperations that make up the whole complex of measures for the implementation of business planning processes as a whole. Next, an integer array of time periods $\boldsymbol{T}_{\tau}=\left\{\tau_{k}\right\}_{k \in 0, n_{\tau}^{(\kappa p .)}}=\boldsymbol{T}_{0}=\left\{\tau_{k}\right\}_{k \in \overline{0,4}}=\left\{\tau_{0}, \tau_{1}, \ldots, \tau_{4}\right\}=\{0 ; 1 ; 2 ; 3 ; 4\}$ is formed to implement the optimization of adaptive control of business planning processes corresponding to events $\{1 ; 2 ; 3 ; 6 ; 9\}$ of the critical path $\boldsymbol{R}_{\tau}^{(\kappa p .)}=\boldsymbol{R}_{0}^{(\kappa p .)}$. 


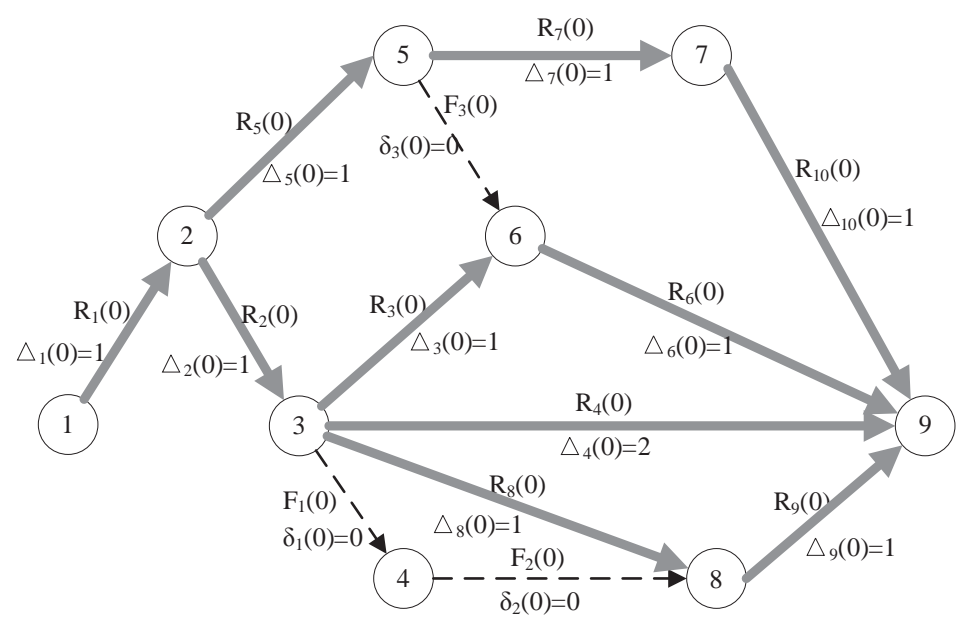

FIGURE 2. Critical paths of a network model for implementing business planning $(\tau=0)$

For the formed network model, based on the found critical path and the corresponding array of the duration of the work-operations, the task of scheduling is solved - the formation of a calendar schedule, i.e., description of the acceptable deadlines for the execution of all work-operations. The schedule for the execution of all work-operations of the business plan in the form of a Gantt chart is shown in Figure 3 and corresponds to 4 weeks of implementation of business planning processes.

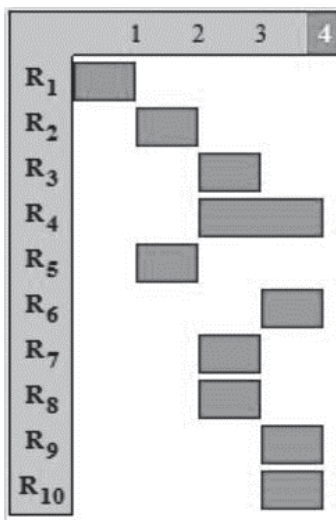

FIGURE 3. Schedule for implementing of business planning $(\tau=0)$

The abscissa indicates the duration of the work-operations of the business plan in weeks; along the ordinate axis ordered work-operations; rectangles with black color indicate non-critical work-operations of the business plan; gray rectangles denote critical operations; rectangles with a dash denote free time reserves for performing work-operations.

At the third stage, for the formed network model, the adaptive control of the processes of the business plan under consideration is implemented, which is carried out on the basis of the proposed method of network formalization and the optimization of adaptive control of business planning processes.

In the process of implementing a business plan, all non-critical work-operations are performed at the earliest possible date prescribed by the current schedule. This assumption does not limit the method used, but is made only to reduce the description of the optimization procedure for adaptive control of business planning processes.

Given that in the initial period of time, i.e., when $\tau=\tau_{0}=0$, there is no delay in the execution of workoperations for which the latest deadline is the beginning of a period of time $\tau_{1}=1$, then applying the new method of network formalization and optimization of adaptive control of business planning processes to the business planning process under consideration, $\tau_{1}$-position is formed that corresponds to the current situation $p\left(\tau_{1}\right)=$ $\left\{\tau_{1}, \overline{\boldsymbol{R}}\left(\tau_{1} \mid \boldsymbol{R}_{0}, \boldsymbol{T}_{\tau}\right)\right\} \in \boldsymbol{P}\left(\tau_{1}\right)$, where $\boldsymbol{P}\left(\tau_{1}\right)$ is the set of all admissible $\tau_{1}$-positions, and the set of work-operations 
$\overline{\boldsymbol{R}}\left(\tau_{1} \mid \boldsymbol{R}_{0}, \boldsymbol{T}_{\tau}\right)=\left\{\bar{R}_{1}\left(\tau_{1}\right), \bar{R}_{2}\left(\tau_{1}\right), \ldots, \bar{R}_{m_{\tau_{1}}}\left(\tau_{1}\right)\right\}=\left\{\bar{R}_{1}\left(\tau_{1}\right)\right\}=\left\{R_{1}(0)\right\}$ is a set consisting of one element, i.e., $m_{\tau_{1}}=1<n_{0}=10 . \quad \quad$ Moreover $p\left(\tau_{1}\right)=\left\{\tau_{1},\left\{\bar{R}_{1}\left(\tau_{1}\right)\right\}\right\}=\quad p^{(e)}\left(\tau_{1}\right)=\left\{\tau_{1},\left\{R_{1}^{(e)}\left(\tau_{1}\right)\right\}\right\}=$ $=\left\{\tau_{1}, \overline{\boldsymbol{R}}^{(e)}\left(\tau_{1} \mid \boldsymbol{R}_{0}, \boldsymbol{T}_{\tau}\right)\right\} \in \boldsymbol{P}\left(\tau_{1}\right)$, where $\overline{\boldsymbol{R}}^{(e)}\left(\tau_{1} \mid \boldsymbol{R}_{0}, \boldsymbol{T}_{\tau}\right)=\left\{R_{1}^{(e)}\left(\tau_{1}\right)\right\}$, and, therefore, is optimal, because the set of work-operations $\left\{\bar{R}_{1}\left(\tau_{1}\right)\right\}=\left\{R_{1}(0)\right\}$ is such, and only such a set of work, which should be completed by the time period $\tau_{1}=1$, provided that they are implemented at the earliest possible dates determined for them by the formed schedule.

In accordance with the strategy for optimal adaptive control of business planning processes $U_{a}^{(e)} \in \boldsymbol{U}_{a}$ defined in the proposed method and the implemented $\tau_{1}$-position $p^{(e)}\left(\tau_{1}\right)=\left\{\tau_{1},\left\{R_{1}^{(e)}\left(\tau_{1}\right)\right\}\right\}=\left\{\tau_{1},\left\{R_{1}(0)\right\}\right\} \in$ $\boldsymbol{P}\left(\tau_{1}\right)$, have:

$$
\begin{gathered}
U_{a}^{(e)}\left(p^{(e)}\left(\tau_{1}\right)\right)=\boldsymbol{R}^{(e)}\left(\tau_{1}\right)=\left\{\boldsymbol{R}_{0} \backslash \overline{\boldsymbol{R}}^{(e)}\left(\tau_{1} \mid \boldsymbol{R}_{0}, \boldsymbol{T}_{\tau}\right)\right\}=\hat{\boldsymbol{R}}^{(e)}\left(\tau_{1} \mid \boldsymbol{R}_{0}, \boldsymbol{T}_{\tau}\right)= \\
=\left\{R_{1}(0), R_{2}(0), \ldots, R_{10}(0)\right\} \backslash\left\{\bar{R}_{1}\left(\tau_{1}\right), \bar{R}_{2}\left(\tau_{1}\right), \ldots, \bar{R}_{m_{\tau_{1}}}\left(\tau_{1}\right)\right\}=\left\{\hat{R}_{1}^{(e)}\left(\tau_{1}\right), \hat{R}_{2}^{(e)}\left(\tau_{1}\right), \ldots, \hat{R}_{\tau_{\tau_{1}}}^{(e)}\left(\tau_{1}\right)\right\}= \\
=\left\{R_{1}\left(\tau_{1}\right), R_{2}\left(\tau_{1}\right), \ldots, R_{n_{\tau_{1}}}\left(\tau_{1}\right)\right\}=\left\{R_{2}(0), R_{3}(0), \ldots, R_{10}(0)\right\}=\boldsymbol{R}_{\tau_{1}},
\end{gathered}
$$

where $n_{\tau_{1}}=n_{0}-m_{\tau_{1}}=10-1=9$. Then, given that, $\boldsymbol{R}\left(\tau_{1}\right)=\left\{R_{1}\left(\tau_{1}\right), R_{2}\left(\tau_{1}\right), \ldots, R_{9}\left(\tau_{1}\right)\right\}=\boldsymbol{R}_{\tau_{1}} \neq \varnothing$ it relies: $s:=s+1 ; t_{s}:=\tau_{1} ; p_{a}^{(e)}\left(t_{s}\right):=p^{(e)}\left(\tau_{1}\right)$; on the basis of the data contained in the array $\Delta(\tau)=\left\{\Delta_{1}(\tau), \Delta_{2}(\tau), \ldots\right.$, $\left.\Delta_{10}(\tau)\right\}=\left\{\Delta_{1}(0), \Delta_{2}(0), \ldots, \Delta_{10}(0)\right\}=\Delta_{\tau}, \quad$ a new array of the duration of the work-operations $\Delta\left(\tau_{1}\right)=\left\{\Delta_{1}\left(\tau_{1}\right), \Delta_{2}\left(\tau_{1}\right), \ldots, \Delta_{9}\left(\tau_{1}\right)\right\}=\Delta_{\tau_{1}}$ corresponding to the new time period $\tau=\tau_{1}$ and to the array of workoperations $\boldsymbol{R}_{\tau_{1}}$ is calculated; relies $\tau:=\tau_{1}=1$.

Then, on the basis of the proposed method, a new task of scheduling is solved, which corresponds to the time period $\tau=1$ and the formed set of work-operations $\boldsymbol{R}^{(e)}(\tau)=\left\{R_{1}(\tau), R_{2}(\tau), \ldots, R_{9}(\tau)\right\}=\left\{R_{2}(0), R_{3}(0), \ldots\right.$, $\left.R_{10}(0)\right\}=\boldsymbol{R}_{\tau_{1}}$, i.e., the only new critical path of the business project $\boldsymbol{R}^{(\kappa p .)}(\tau)==\left\{R_{1}^{(\kappa p .)}(1 ; 2), R_{2}^{(\kappa p .)}(2 ; 3)\right.$, $\left.R_{10}^{(k p .)}(3 ; 4)\right\}=\boldsymbol{R}_{\tau}^{(\kappa p .)}$ is being formed, which is part of the previous critical path (Figure 2) and consists of a set of work-operations $\left\{R_{1}(\tau), R_{2}(\tau), R_{5}(\tau)\right\}=\left\{R_{2}(0), R_{3}(0), R_{6}(0)\right\}$, as well as a new calendar schedule, which is part of the previous schedule (Figure 3). These elements of solving the problem under consideration correspond to a new array of time periods for implementing the optimization of adaptive control of business planning processes $\boldsymbol{T}_{\tau}=\left\{\tau_{k}\right\}_{k \in 1, n_{\tau}^{(\kappa p .)}}=\left\{\tau_{k}\right\}_{k \in \overline{0,3}}=\{1,2,3,4\}=\left\{\tau_{0}, \tau_{1}, \tau_{2}, \tau_{3}\right\}$, where $\tau_{0}=\tau=1$, and along with critical time $T_{\tau}^{(e)}=4$ they are remembered.

Considering that during the time period $\tau=1$ there is no delay in the execution of work-operations for which the most recent deadline is time $\tau_{1}=2$, then, similarly to the procedure described for the time period $\tau=0$, the following elements of the proposed solution are constructed:

1) $\tau_{1}$-position $\left(\tau_{1}=2\right)$ of the project $p\left(\tau_{1}\right)=\left\{\tau_{1}, \overline{\boldsymbol{R}}\left(\tau_{1} \mid \boldsymbol{R}_{0}, \boldsymbol{T}_{\tau}\right)\right\} \in \boldsymbol{P}\left(\tau_{1}\right)$, where the set of work-operations $\overline{\boldsymbol{R}}\left(\tau_{1} \mid \boldsymbol{R}_{0}, \boldsymbol{T}_{\tau}\right)=\left\{\bar{R}_{1}\left(\tau_{1}\right), \bar{R}_{2}\left(\tau_{1}\right), \ldots, \bar{R}_{m_{\tau_{1}}}\left(\tau_{1}\right)\right\}=\left\{\bar{R}_{1}\left(\tau_{1}\right), \bar{R}_{2}\left(\tau_{1}\right), \bar{R}_{3}\left(\tau_{1}\right)\right\}$ is a set consisting of 3 elements, i.e., 
$m_{\tau_{1}}=3<n_{0}=10$. In this case $p\left(\tau_{1}\right)=\left\{\tau_{1},\left\{\bar{R}_{1}\left(\tau_{1}\right),\left\{\bar{R}_{2}\left(\tau_{1}\right),\left\{\bar{R}_{3}\left(\tau_{1}\right)\right\}\right\}=p^{(e)}\left(\tau_{1}\right)=\left\{\tau_{1},\left\{R_{1}^{(e)}\left(\tau_{1}\right), R_{2}^{(e)}\left(\tau_{1}\right)\right.\right.\right.\right.$, $\left.\left.R_{3}^{(e)}\left(\tau_{1}\right)\right\}\right\}=\left\{\tau_{1}, \overline{\boldsymbol{R}}^{(e)}\left(\tau_{1} \mid \boldsymbol{R}_{0}, \boldsymbol{T}_{\tau}\right)\right\} \in \boldsymbol{P}\left(\tau_{1}\right)$, where $\overline{\boldsymbol{R}}^{(e)}\left(\tau_{1} \mid \boldsymbol{R}_{0}, \boldsymbol{T}_{\tau}\right)=\left\{R_{1}^{(e)}\left(\tau_{1}\right), R_{2}^{(e)}\left(\tau_{1}\right), R_{3}^{(e)}\left(\tau_{1}\right)\right\}=\left\{R_{1}(0)\right.$, $\left.R_{2}(0), R_{5}(0)\right\}$;

2) the output array of the implementation of the strategy of optimal adaptive control of business planning processes $U_{a}^{(e)}\left(p^{(e)}\left(\tau_{1}\right)\right)=\boldsymbol{R}^{(e)}\left(\tau_{1}\right)=\left\{\boldsymbol{R}_{0} \backslash \overline{\boldsymbol{R}}^{(e)}\left(\tau_{1} \mid \boldsymbol{R}_{0}, \boldsymbol{T}_{\tau}\right)\right\}=\hat{\boldsymbol{R}}^{(e)}\left(\tau_{1} \mid \boldsymbol{R}_{0}, \boldsymbol{T}_{\tau}\right)=\left\{\hat{R}_{1}^{(e)}\left(\tau_{1}\right), \hat{\boldsymbol{R}}_{2}^{(e)}\left(\tau_{1}\right), \ldots\right.$, $\left.\hat{R}_{n_{\tau_{1}}}^{(e)}\left(\tau_{1}\right)\right\}=\left\{R_{1}\left(\tau_{1}\right), R_{2}\left(\tau_{1}\right), \ldots, R_{n_{\tau_{1}}}\left(\tau_{1}\right)\right\}=\left\{R_{1}\left(\tau_{1}\right), R_{2}\left(\tau_{1}\right), \ldots, R_{7}\left(\tau_{1}\right)\right\}=\left\{R_{3}(0), R_{4}(0), R_{6}(0), R_{7}(0), \ldots\right.$, $\left.R_{10}(0)\right\}=\boldsymbol{R}_{\tau_{1}}$, where $n_{\tau_{1}}=n_{0}-m_{\tau_{1}}=10-3=7$; Considering that $\boldsymbol{R}_{\tau_{1}} \neq \varnothing$, it relies: $s:=s+1 ; t_{s}:=\tau_{1}$; $p_{a}^{(e)}\left(t_{s}\right):=p^{(e)}\left(\tau_{1}\right)$;

3) a new array of the duration of the execution of work-operations $\Delta\left(\tau_{1}\right)=\left\{\Delta_{1}\left(\tau_{1}\right), \Delta_{2}\left(\tau_{1}\right), \ldots, \Delta_{7}\left(\tau_{1}\right)\right\}=$ $\left\{\Delta_{3}(0), \Delta_{4}(0), \Delta_{6}(0), \Delta_{7}(0), \ldots, \Delta_{10}(0)\right\}=\Delta_{\tau_{1}}$ corresponding to the array of work-operations $\boldsymbol{R}^{(e)}\left(\tau_{1}\right)=$ $\left\{R_{1}\left(\tau_{1}\right), R_{2}\left(\tau_{1}\right), \ldots, R_{7}\left(\tau_{1}\right)\right\}=\left\{R_{3}(0), R_{4}(0), R_{6}(0), R_{7}(0), \ldots, R_{10}(0)\right\}==\boldsymbol{R}_{\tau_{1}}$, corresponding to a new period of time $\tau=\tau_{1}$; relies $\tau:=\tau_{1}=2$.

Further, on the basis of the proposed method, a new scheduling task is solved corresponding to the time period $\tau=2$ and the formed set of work-operations $\boldsymbol{R}^{(e)}(\tau)=\left\{R_{1}(\tau), R_{2}(\tau), \ldots, \quad R_{7}(\tau)\right\}=\left\{R_{3}(0), R_{4}(0), R_{6}(0)\right.$, $\left.R_{7}(0), \ldots, R_{10}(0)\right\}=\boldsymbol{R}_{\tau_{1}}$, i.e., the only new critical path of the considered business planning process $\boldsymbol{R}^{(\kappa p .)}(\tau)=$ $\left\{R_{1}^{(\kappa p .)}(2 ; 3), R_{2}^{(\kappa p .)}(3 ; 4)\right\}=\boldsymbol{R}_{\tau}^{(\kappa p .)}$ is being formed, which is part of the previous critical path (Figure 2) and consists of a set of work-operations $\left\{R_{1}(\tau), R_{3}(\tau)\right\}=\left\{R_{3}(0), R_{6}(0)\right\}$, as well as a new calendar schedule, which is part of the previous schedule (Figure 3). These elements of solving the task under consideration correspond to a new array of time periods for implementing the optimization of adaptive control of business planning processes $\boldsymbol{T}_{\tau}=\left\{\tau_{k}\right\}_{k \in 1, n_{\tau}^{(k p .)}}=\left\{\tau_{k}\right\}_{k \in \overline{0,2}}=\{2,3,4\}=\left\{\tau_{0}, \tau_{1}, \tau_{2}\right\}$, where $\tau_{0}=\tau=2$ and along with critical time $T_{\tau}^{(e)}=4$ they are remembered.

When performing the work-operation $R_{1}(\tau)=R_{3}(0)$ - "Cost calculation" there was a delay in the implementation of the business plan due to an increase in the time for its execution by 1 week. Moreover, by the beginning of the time period $\tau_{1}=3$, i.e., in the time period $\tau=2$, only a part of it $\widetilde{R}_{1}(\tau)=\widetilde{R}_{3}(0)$ is completed, and the remaining part $\breve{R}_{1}(\tau)=\breve{R}_{3}(0)$ is performed in the time period $\tau_{1}=3$, while have $R_{1}(\tau)=\widetilde{R}_{1}(\tau) \cup \breve{R}_{1}(\tau)==$ $\widetilde{R}_{3}(0) \cup \breve{R}_{3}(0)=R_{3}(0)$. Let us denote $\widetilde{\Delta}_{1}(\tau)=\widetilde{\Delta}_{3}(0)=1$ the duration of the work-operation $\widetilde{R}_{1}(\tau)=\widetilde{R}_{3}(0)$ and $\breve{\Delta}_{1}(\tau)=\breve{\Delta}_{3}(0)=1$ the duration of the work-operation $\breve{R}_{1}(\tau)=\breve{R}_{3}(0)$, then have: $\Delta_{1}(\tau)=\Delta_{3}(0)+1=1+1=2$. Between events with numbers 3 and 6 , we introduce event A3, which corresponds to the completion of the workoperation $\widetilde{R}_{1}(\tau)=\widetilde{R}_{3}(0)$ and the beginning of the work-operation $\breve{R}_{1}(\tau)=\breve{R}_{3}(0)$, i.e., completion of the control period $\tau=2$ and the beginning of the control period $\tau_{1}=\tau+1=2+1=3$ (Figure 4). For the current new situation, i.e., changes in the array of work-operations $\boldsymbol{R}^{(e)}(\tau)=\left\{R_{1}(\tau), R_{2}(\tau), \ldots, R_{7}(\tau)\right\}=$ $\left\{R_{3}(0), R_{4}(0), R_{6}(0), R_{7}(0), \ldots, R_{10}(0)\right\}=\boldsymbol{R}_{\tau}$, namely, taking into account the increase in the duration of the work-operation $R_{1}(\tau)=R_{3}(0), \quad$ it $\quad$ is $\quad$ described $\quad$ by $\quad$ the $\quad$ array $\boldsymbol{R}^{(e)}(\tau)=\left\{R_{1}(\tau), R_{2}(\tau), \ldots, R_{8}(\tau)\right\}=$ 
$\left\{\widetilde{R}_{3}(0), \breve{R}_{3}(0), R_{4}(0),=\mathrm{R}_{6}(0), R_{7}(0), \ldots, R_{10}(0)\right\}=\boldsymbol{R}_{\tau}$, the formation of a new calendar schedule (Figure 5). Given that the operation $R_{1}(\tau)=R_{3}(0)$ is a critical operation and enters into a critical path, in this case the duration of the business plan as a whole will increase by 1 week and the total duration of the business plan as a whole will total 5 weeks, i.e., then have: $T_{\tau}^{(e)}:=4+1=5$.

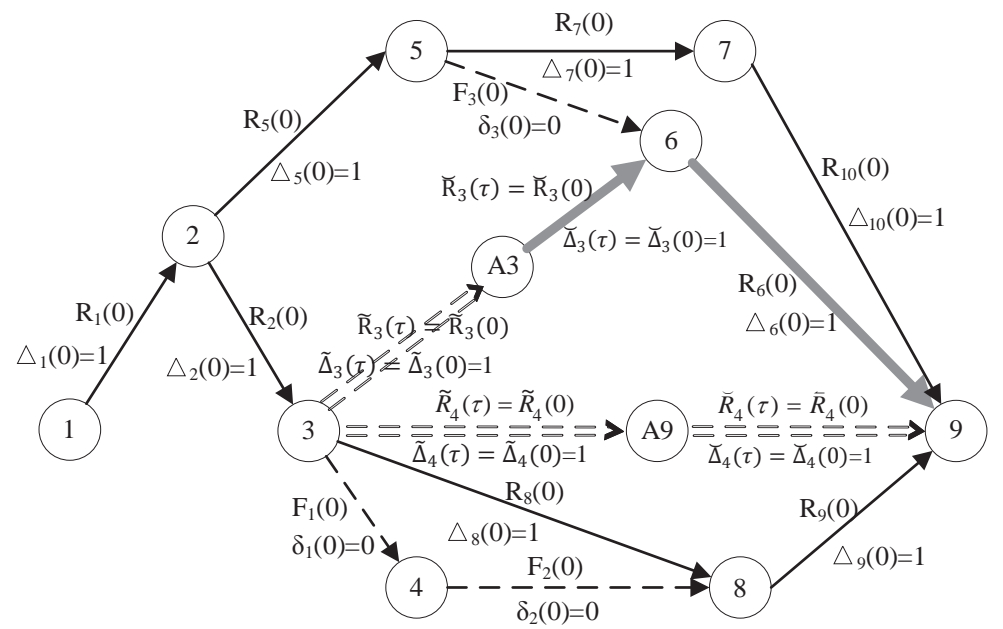

FIGURE 4. Critical path of the network model for implementing business planning $(\tau=3)$



FIGURE 5. Schedule for implementing of business planning $(\tau=3)$

In the period of time $\tau_{1}=3 \tau_{1}$-position is formed corresponding to the current situation $p\left(\tau_{1}\right)=\left\{\tau_{1}, \overline{\boldsymbol{R}}\left(\tau_{1} \mid \boldsymbol{R}_{0}, \boldsymbol{T}_{\tau}\right)\right\} \in \boldsymbol{P}\left(\tau_{1}\right)$, where the set of work-operations $\overline{\boldsymbol{R}}\left(\tau_{1} \mid \boldsymbol{R}_{0}, \boldsymbol{T}_{\tau}\right)==\left\{\bar{R}_{1}\left(\tau_{1}\right), \overline{\boldsymbol{R}}_{2}\left(\tau_{1}\right), \ldots\right.$, $\left.\bar{R}_{m_{\tau_{1}}}\left(\tau_{1}\right)\right\}=\left\{\bar{R}_{1}\left(\tau_{1}\right), \bar{R}_{2}\left(\tau_{1}\right), \ldots, \bar{R}_{7}\left(\tau_{1}\right)\right\}$ is a set of 7 elements, i.e., $m_{\tau_{1}}=7<n_{0}=10$. Moreover, $p\left(\tau_{1}\right)=$ $\left\{\tau_{1},\left\{\bar{R}_{1}\left(\tau_{1}\right), \bar{R}_{2}\left(\tau_{1}\right), \ldots, \bar{R}_{7}\left(\tau_{1}\right)\right\}\right\} \neq p^{(e)}\left(\tau_{1}\right)=\left\{\tau_{1},\left\{R_{1}^{(e)}\left(\tau_{1}\right), R_{2}^{(e)}\left(\tau_{1}\right), \ldots, R_{7}^{(e)}\left(\tau_{1}\right)\right\}\right\}=$ $\left\{\tau_{1}, \overline{\boldsymbol{R}}^{(e)}\left(\tau_{1} \mid \boldsymbol{R}_{0}, \boldsymbol{T}_{\tau}\right)\right\} \in \boldsymbol{P}\left(\tau_{1}\right)$, т.e. $p\left(\tau_{1}\right) \in\left\{\boldsymbol{P}\left(\tau_{1}\right) \backslash\left\{p^{(e)}\left(\tau_{1}\right)\right\}\right\}$ and, therefore, is not an optimal $\tau_{1}$-position, since in the set of work-operations $\left\{\bar{R}_{1}\left(\tau_{1}\right), \bar{R}_{2}\left(\tau_{1}\right), \ldots, \bar{R}_{7}\left(\tau_{1}\right)\right\}=\left\{R_{1}(0), R_{2}(0), \ldots, R_{5}(0), R_{7}(0), R_{8}(0)\right\}$ to the beginning of the execution of the period of time $\tau_{1}=3$ the work $\bar{R}_{3}\left(\tau_{1}\right)=R_{3}(0)$ and $\bar{R}_{4}\left(\tau_{1}\right)=R_{4}(0)$ is only partially completed (provided that they are completed at the earliest possible date), namely, only the corresponding parts $\widetilde{R}_{3}\left(\tau_{1}\right)=\widetilde{R}_{3}(0)$ are completed, where $\bar{R}_{3}\left(\tau_{1}\right)=\widetilde{R}_{3}\left(\tau_{1}\right) \cup \breve{R}_{3}\left(\tau_{1}\right)=\widetilde{R}_{3}(0) \cup \breve{R}_{3}(0)=R_{3}(0)$ and $\breve{R}_{3}(0)-$ the remaining part of this work, and $\widetilde{R}_{4}\left(\tau_{1}\right)=\widetilde{R}_{4}(0)$, where $\bar{R}_{4}\left(\tau_{1}\right)=\widetilde{R}_{4}\left(\tau_{1}\right) \cup \breve{R}_{4}\left(\tau_{1}\right)=\widetilde{R}_{4}(0) \cup \breve{R}_{4}(0)=R_{4}(0)$ and 
$\breve{R}_{4}(0)$ - the remaining part of this work. Let us denote: $\widetilde{\Delta}_{3}\left(\tau_{1}\right)=\widetilde{\Delta}_{3}(0)=1-$ the time in weeks spent on the work $\widetilde{R}_{3}\left(\tau_{1}\right)=\widetilde{R}_{3}(0)$, and after $\breve{\Delta}_{3}\left(\tau_{1}\right)=\breve{\Delta}_{3}(0)=1-$ the time in weeks needed to complete the work $\breve{R}_{3}\left(\tau_{1}\right)=\breve{R}_{3}(0)$. Similarly, we denote: $\widetilde{\Delta}_{4}\left(\tau_{1}\right)=\widetilde{\Delta}_{4}(0)=1$ the time in weeks spent on the work $\widetilde{R}_{4}\left(\tau_{1}\right)=\widetilde{R}_{4}(0)$, and after $\breve{\Delta}_{4}\left(\tau_{1}\right)=\breve{\Delta}_{4}(0)=1$ - the time in weeks needed to complete the work $\breve{R}_{4}\left(\tau_{1}\right)=\breve{R}_{4}(0)$. In Fig. 4 introduce between events with numbers 3 and 9 event A9, corresponding to the beginning of a period of time $\tau_{1}=3$. Then the work $\widetilde{R}_{4}\left(\tau_{1}\right)=\widetilde{R}_{4}(0)$ leaves the event at number 3 and enters the event A9, and the work $\breve{R}_{4}\left(\tau_{1}\right)=\breve{R}_{4}(0)$ leaves the event A9 and enters the event at number 9 (both of these works are depicted by directional double dotted line segments-edges). Define a set $\breve{\boldsymbol{R}}\left(\tau_{1}\right)=\left\{\breve{R}_{1}\left(\tau_{1}\right), \breve{R}_{2}\left(\tau_{1}\right), \ldots, \quad \breve{R}_{l_{1}}\left(\tau_{1}\right)\right\}=\left\{\breve{R}_{1}\left(\tau_{1}\right), \breve{R}_{2}\left(\tau_{1}\right)\right\}=\left\{\breve{R}_{3}(0), \breve{R}_{4}(0)\right\}$ that contains the incomplete parts of the work-operations $\bar{R}_{3}\left(\tau_{1}\right)=R_{3}(0)$ and $\bar{R}_{4}\left(\tau_{1}\right)=R_{4}(0)$, where $l_{\tau_{1}}=2$.

In accordance with a certain strategy of optimal adaptive control of business planning processes $U_{a}^{(e)} \in \boldsymbol{U}_{a}$ and the implemented $\tau_{1}$-position $p\left(\tau_{1}\right)=\left\{\tau_{1},\left\{\bar{R}_{1}\left(\tau_{1}\right), \bar{R}_{2}\left(\tau_{1}\right), \ldots, \bar{R}_{7}\left(\tau_{1}\right)\right\}\right\}=\left\{\tau_{1},\left\{R_{1}(0), R_{2}(0), \ldots, R_{5}(0), R_{7}(0)\right.\right.$, $\left.\left.R_{8}(0)\right\}\right\} \in\left\{\boldsymbol{P}\left(\tau_{1}\right) \backslash\left\{p^{(e)}\left(\tau_{1}\right)\right\}\right\}$, have:

$$
\begin{gathered}
U_{a}^{(e)}\left(p^{(e)}\left(\tau_{1}\right)\right)=\boldsymbol{R}\left(\tau_{1}\right)=\breve{\boldsymbol{R}}\left(\tau_{1}\right) \cup\left\{\boldsymbol{R}_{0} \backslash \overline{\boldsymbol{R}}\left(\tau_{1} \mid \boldsymbol{R}_{0}, \boldsymbol{T}_{\tau}\right)\right\}=\hat{\boldsymbol{R}}\left(\tau_{1} \mid \boldsymbol{R}_{0}, \boldsymbol{T}_{\tau}\right)= \\
=\left\{\breve{R}_{3}(0), \breve{R}_{4}(0)\right\} \bigcup\left\{R_{1}(0), R_{2}(0), \ldots, R_{10}(0)\right\} \backslash\left\{\bar{R}_{1}\left(\tau_{1}\right), \bar{R}_{2}\left(\tau_{1}\right), \ldots, \bar{R}_{m_{\tau_{1}}}\left(\tau_{1}\right)\right\}=\left\{\hat{R}_{1}\left(\tau_{1}\right), \hat{R}_{2}\left(\tau_{1}\right), \ldots, \hat{R}_{n_{\tau_{1}}}\left(\tau_{1}\right)\right\}= \\
=\left\{R_{1}\left(\tau_{1}\right), R_{2}\left(\tau_{1}\right), \ldots, R_{n_{\tau_{1}}}\left(\tau_{1}\right)\right\}=\left\{\breve{R}_{3}(0), \breve{R}_{4}(0), R_{6}(0), R_{9}(0), R_{10}(0)\right\}=\boldsymbol{R}_{\tau_{1}},
\end{gathered}
$$

where $n_{\tau_{1}}=n_{0}-m_{\tau_{1}}+l_{\tau_{1}}=10-7+2=5$. Then, given that $\boldsymbol{R}_{\tau_{1}} \neq \varnothing$, it relies: $s:=s+1 ; t_{s}:=\tau_{1} ; p_{a}^{(e)}\left(t_{s}\right):=$ $p\left(\tau_{1}\right)$; based on the data contained in the array $\Delta(\tau)=\left\{\Delta_{1}(\tau), \Delta_{2}(\tau), \ldots, \Delta_{7}(\tau)\right\}=$ $=\left\{\Delta_{3}(0), \Delta_{4}(0), \Delta_{6}(0), \Delta_{7}(0), \ldots, \Delta_{10}(0)\right\}=\Delta_{\tau}$, as well as the values $\tilde{\Delta}_{3}\left(\tau_{1}\right)=\tilde{\Delta}_{3}(0)=1$ and $\tilde{\Delta}_{4}\left(\tau_{1}\right)=\widetilde{\Delta}_{4}(0)=1$ , a new array of the duration of the execution of work-operations $\Delta\left(\tau_{1}\right)=\left\{\Delta_{1}\left(\tau_{1}\right), \Delta_{2}\left(\tau_{1}\right), \ldots, \Delta_{5}\left(\tau_{1}\right)\right\}=$ $\left\{\breve{\Delta}_{3}(0), \breve{\Delta}_{4}(0), \Delta_{6}(0), \Delta_{9}(0), \Delta_{10}(0)\right\}=\Delta_{\tau_{1}}$ is calculated; relies $\tau:=\tau_{1}=3$.

Further a new scheduling task is solved that corresponds to the time period $\tau=3$ and the formed set of workoperations $\boldsymbol{R}^{(e)}(\tau)=\left\{R_{1}(\tau), R_{2}(\tau), \ldots, R_{5}(\tau)\right\}=\left\{\breve{R}_{3}(0), \breve{R}_{4}(0), R_{6}(0), R_{9}(0), R_{10}(0)\right\}=\boldsymbol{R}_{\tau_{1}}$, i.e., a single new critical path is being formed for the business planning processes $\boldsymbol{R}^{(\kappa p .)}(\tau)=\left\{R_{1}^{(\kappa p .)}(3 ; 4), R_{2}^{(\kappa p .)}(4 ; 5)\right\}=\boldsymbol{R}_{\tau}^{(\kappa p .)}$, which consists of a set of work-operations $\left\{R_{1}(\tau), R_{3}(\tau)\right\}=\left\{\breve{R}_{3}(0), R_{6}(0)\right\}$ (Figure 4), as well as a new calendar schedule, which is part of the previous schedule (Figure 5). These elements of solving the problem under consideration correspond to a new array of time periods for implementing optimization of adaptive control of business planning processes $\boldsymbol{T}_{\tau}=\left\{\tau_{k}\right\}_{k \in 1, n_{\tau}^{(k p .)}}=\left\{\tau_{k}\right\}_{k \in \overline{0,2}}=\{3,4,5\}==\left\{\tau_{0}, \tau_{1}, \tau_{2}\right\}$, where $\tau_{0}=\tau=3$, and along with critical time $T_{\tau}^{(e)}=5$ they are remembered.

Considering that during the time period $\tau=3$ there is no delay in the execution of work-operations for which the most recent deadline is time $\tau_{1}=4$, then similarly to the procedure described for the time period $\tau=0$, the following elements of the proposed solution are constructed: 
1) $\tau_{1}$-position $\left(\tau_{1}=4\right)$ of the project $p\left(\tau_{1}\right)=\left\{\tau_{1}, \overline{\boldsymbol{R}}\left(\tau_{1} \mid \boldsymbol{R}_{0}, \boldsymbol{T}_{\tau}\right)\right\} \in \boldsymbol{P}\left(\tau_{1}\right)$, where the set of work-operations $\overline{\boldsymbol{R}}\left(\tau_{1} \mid \boldsymbol{R}_{0}, \boldsymbol{T}_{\tau}\right)=\left\{\bar{R}_{1}\left(\tau_{1}\right), \bar{R}_{2}\left(\tau_{1}\right), \ldots, \bar{R}_{m_{\tau_{1}}}\left(\tau_{1}\right)\right\}=\left\{\bar{R}_{1}\left(\tau_{1}\right), \bar{R}_{2}\left(\tau_{1}\right), \ldots, \bar{R}_{9}\left(\tau_{1}\right)\right\}$ is a set consisting of 9 elements, i.e., $m_{\tau_{1}}=9<n_{0}=10$.

2) the output array of the implementation of the strategy of optimal adaptive control of business planning processes $U_{a}^{(e)}\left(p^{(e)}\left(\tau_{1}\right)\right)=\boldsymbol{R}^{(e)}\left(\tau_{1}\right)=\left\{\boldsymbol{R}_{0} \backslash \overline{\boldsymbol{R}}^{(e)}\left(\tau_{1} \mid \boldsymbol{R}_{0}, \boldsymbol{T}_{\tau}\right)\right\}=\hat{\boldsymbol{R}}^{(e)}\left(\tau_{1} \mid \boldsymbol{R}_{0}, \boldsymbol{T}_{\tau}\right)=\left\{\hat{R}_{1}^{(e)}\left(\tau_{1}\right), \hat{\boldsymbol{R}}_{2}^{(e)}\left(\tau_{1}\right), \ldots\right.$, $\left.\hat{R}_{n_{\tau_{1}}}^{(e)}\left(\tau_{1}\right)\right\}=\left\{R_{1}\left(\tau_{1}\right), R_{2}\left(\tau_{1}\right), \ldots, R_{n_{\tau_{1}}}\left(\tau_{1}\right)\right\}=\left\{R_{1}\left(\tau_{1}\right)\right\}=\left\{R_{6}(0)\right\}=\boldsymbol{R}_{\tau_{1}}$, where $n_{\tau_{1}}=n_{0}-m_{\tau_{1}}=10-9=1 ;$

3) a new array of the duration of the work-operations $\Delta\left(\tau_{1}\right)=\left\{\Delta_{1}\left(\tau_{1}\right)\right\}=\left\{\Delta_{6}(0)\right\}=\Delta_{\tau_{1}}$, corresponding to the array of work-operations $\boldsymbol{R}^{(e)}\left(\tau_{1}\right)=\left\{R_{1}\left(\tau_{1}\right)\right\}=\left\{R_{6}(0)\right\}=\boldsymbol{R}_{\tau_{1}}$, corresponding to a new period of time $\tau=\tau_{1}$.

Next, a new scheduling task is solved, corresponding to the time period $\tau=4$ and the formed set of workoperations $\boldsymbol{R}^{(e)}(\tau)=\left\{R_{1}(\tau)\right\}=\left\{R_{6}(0)\right\}=\boldsymbol{R}_{\tau_{1}}$, i.e., a single new critical path $\boldsymbol{R}^{(\kappa p .)}(\tau)=\left\{R_{1}^{(k p .)}(4 ; 5)\right\}=\boldsymbol{R}_{\tau}^{(\kappa p .)}$ is formed, which is part of the previous critical path (Figure 4) and consists of a single work-operation $\left\{R_{1}(\tau)\right\}=$ $\left\{R_{6}(0)\right\}$, as well as a new calendar schedule, which is part of the previous graph (Figure 5). These elements of the solution correspond to a new array of time periods for implementing the optimization of adaptive control of business planning processes $\boldsymbol{T}_{\tau}=\left\{\tau_{k}\right\}_{k \in 1, n_{\tau}^{(k p .)}}=\left\{\tau_{k}\right\}_{k \in \overline{0,1}}=\{4,5\}=\left\{\tau_{0}, \tau_{1}\right\}$ where $\tau_{0}=\tau=4$ and along with critical time $T_{\tau}^{(e)}=5$ they are remembered.

In the period of time $\tau=4$ again there is no delay in the execution of work-operations for which the most recent deadline is the critical time $T_{\tau}^{(e)}=\tau_{1}=5$. Then, by the beginning of the time period $\tau_{1}=5$ in whole or in part of the operations, for which the least early date for their execution is time $\tau=0$, the following elements of the proposed solution are constructed:

1) $\tau_{1}$-position $\left(\tau_{1}=5\right)$ of the project $p\left(\tau_{1}\right)=\left\{\tau_{1}, \overline{\boldsymbol{R}}\left(\tau_{1} \mid \boldsymbol{R}_{0}, \boldsymbol{T}_{\tau}\right)\right\} \in \boldsymbol{P}\left(\tau_{1}\right)$, where the set of work-operations $\overline{\boldsymbol{R}}\left(\tau_{1} \mid \boldsymbol{R}_{0}, \boldsymbol{T}_{\tau}\right)=\left\{\bar{R}_{1}\left(\tau_{1}\right), \bar{R}_{2}\left(\tau_{1}\right), \ldots, \bar{R}_{m_{\tau_{1}}}\left(\tau_{1}\right)\right\}=\left\{\bar{R}_{1}\left(\tau_{1}\right), \bar{R}_{2}\left(\tau_{1}\right), \ldots, \bar{R}_{10}\left(\tau_{1}\right)\right\}$ is a set consisting of 10 elements, i.e. $m_{\tau_{1}}=10=n_{0}=10 . \quad$ In $\quad$ this $\quad$ case $\quad p\left(\tau_{1}\right)=\left\{\tau_{1},\left\{\bar{R}_{1}\left(\tau_{1}\right),\left\{\bar{R}_{2}\left(\tau_{1}\right), \ldots,\left\{\bar{R}_{10}\left(\tau_{1}\right)\right\}\right\}=p^{(e)}\left(\tau_{1}\right)=\left\{\tau_{1}\right.\right.\right.$, $\left.\left\{R_{1}^{(e)}\left(\tau_{1}\right), R_{2}^{(e)}\left(\tau_{1}\right), \ldots, R_{10}^{(e)}\left(\tau_{1}\right)\right\}\right\}=\left\{\tau_{1}, \overline{\boldsymbol{R}}^{(e)}\left(\tau_{1} \mid \boldsymbol{R}_{0}, \boldsymbol{T}_{\tau}\right)\right\} \in \boldsymbol{P}\left(\tau_{1}\right), \quad$ where $\quad \overline{\boldsymbol{R}}^{(e)}\left(\tau_{1} \mid \boldsymbol{R}_{0}, \boldsymbol{T}_{\tau}\right)=\quad\left\{R_{1}^{(e)}\left(\tau_{1}\right)\right.$, $\left.R_{2}^{(e)}\left(\tau_{1}\right), \ldots, R_{10}^{(e)}\left(\tau_{1}\right)\right\}=\left\{R_{1}(0), R_{2}(0), \ldots, R_{10}(0)\right\}$;

2) the output array of the implementation of the strategy of optimal adaptive control of business planning processes $U_{a}^{(e)}\left(p^{(e)}\left(\tau_{1}\right)\right)=\boldsymbol{R}^{(e)}\left(\tau_{1}\right)=\left\{\boldsymbol{R}_{0} \backslash \overline{\boldsymbol{R}}^{(e)}\left(\tau_{1} \mid \boldsymbol{R}_{0}, \boldsymbol{T}_{\tau}\right)\right\}=\hat{\boldsymbol{R}}^{(e)}\left(\tau_{1} \mid \boldsymbol{R}_{0}, \boldsymbol{T}_{\tau}\right)=\left\{\hat{R}_{1}^{(e)}\left(\tau_{1}\right), \hat{R}_{2}^{(e)}\left(\tau_{1}\right), \ldots\right.$, $\left.\hat{R}_{n_{\tau_{1}}}^{(e)}\left(\tau_{1}\right)\right\}=\left\{R_{1}\left(\tau_{1}\right), R_{2}\left(\tau_{1}\right), \ldots, R_{n_{\tau_{1}}}\left(\tau_{1}\right)\right\}=\varnothing=\boldsymbol{R}_{\tau_{1}}$, where $n_{\tau_{1}}=n_{0}-m_{\tau_{1}}=10-10=0$.

Then, based on the strategy of optimal adaptive control of business planning processes defined in the method used $U_{a}^{(e)} \in \boldsymbol{U}_{a}$ and considering that $\left.\overline{\boldsymbol{R}}^{(e)}\left(\tau_{1} \mid \boldsymbol{R}_{0}, \boldsymbol{T}_{\tau}\right)\right\}=\left\{R_{1}^{(e)}\left(\tau_{1}\right), R_{2}^{(e)}\left(\tau_{1}\right), \ldots, R_{10}^{(e)}\left(\tau_{1}\right)\right\}=\left\{R_{1}(0), R_{2}(0), \ldots\right.$, $\left.R_{10}(0)\right\}$, i.e., $\quad m_{\tau_{1}}=n_{0}=10$ and $\boldsymbol{R}^{(e)}\left(\tau_{1}\right)=\boldsymbol{R}_{\tau_{1}}=\varnothing$, then it turns out that by the time period $T_{\tau}^{(e)}=\tau+1=\tau_{1}=5$ all the work-operations were completed that described the business planning processes under consideration. Therefore, the process of optimizing the adaptive control of the considered business planning 
processes, i.e., the formation and implementation of the strategy $U_{a}^{(e)} \in \boldsymbol{U}_{a}$ is considered completed; relies: $s:=s+1 ; t_{s}:=\tau_{1}=5 ; p_{a}^{(e)}\left(t_{s}\right):=p^{(e)}\left(\tau_{1}\right)$ and the transition to the formation of the final (output) results of solving this problem is carried out.

At the fourth stage, the output results of the process of optimizing adaptive control of the business project under consideration are formed, i.e., a description of the elements of the formation and implementation of the strategy $U_{a}^{(e)} \in \boldsymbol{U}_{a}$ is carried out, in accordance with paragraph 13 and paragraph 14 given in the first part of the article describing the proposed method, and there is the following data: $\boldsymbol{R}_{a}^{(e)}=\boldsymbol{R}(0)=\left\{R_{1}(0), R_{2}(0), \ldots, R_{n_{0}}(0)\right\}=\boldsymbol{R}_{0}==$ $\left\{R_{1}(0), R_{2}(0), \ldots, R_{10}(0)\right.$ - the initial set of work-operations (processes) of the business project; $\boldsymbol{W} \boldsymbol{M}_{a}^{(e)}=$ $=\boldsymbol{W M}_{0}^{(e)}(\boldsymbol{R}(0))$ - optimal network model; $p_{a}^{(e)}\left(t_{k}\right)$ - a set of $t_{k}$-positions $k \in \overline{1, s}$ corresponding to the implementation of the strategy of optimal adaptive control of business planning processes $U_{a}^{(e)}$; $\boldsymbol{T}_{a}^{(e)}=T_{\tau}^{(e)}=T_{4}^{(e)}=5$ - optimal time for the implementation of a business project, corresponding to the implementation of the strategy for optimal adaptive control of business planning processes $U_{a}^{(e)}$.

Note that if you do not apply the proposed method for optimizing adaptive control of business planning processes, then already in the period of time that answers $\tau_{1}=3$ when the work-operation $R_{1}\left(\tau_{1}\right)=\widetilde{R}_{1}\left(\tau_{1}\right) \cup \breve{R}_{1}\left(\tau_{1}\right)=\widetilde{R}_{3}(0) \cup \breve{R}_{3}(0)=R_{3}(0)$ has not yet been fully implemented, but only a part of it $\widetilde{R}_{1}\left(\tau_{1}\right)=\widetilde{R}_{3}(0)$ has been implemented, the implementation of the business plan in accordance with the calendar the schedule developed for the initial period of time $\tau=0$ will lead to the intersection of the execution periods, the works included in it $R_{1}\left(\tau_{1}\right)=R_{3}(0)$ and $R_{3}\left(\tau_{1}\right)=R_{6}(0)$, which is unacceptable from the conditions of its implementation and will lead to the failure to complete the business project as a whole.

Thus, from the obtained results of solving the model problem of optimizing adaptive control of business planning, can conclude that the application of the proposed new method allows the control process to provide feedback in the form of appropriate reactions control action to unforeseen changes in situations during the implementation of business planning and get optimal result - best time to complete the business project as a whole.

\section{CONCLUSIONS}

The model task considered in this article illustrates the actual problem of managing works in the restaurant business. An important feature of the proposed new method of network formalization and optimization of adaptive control of business planning processes is that it implements the possibility of control based on the feedback principle. Continuous monitoring of the implementation of business planning processes is consistently used to form and implement a strategy for optimal adaptive control of these processes.

The use of adaptive principles for building a model for managing business planning processes can significantly reduce the impact of uncertainty on the result of a specific business project, thereby compensating for the lack of a priori information at the design stage.

Further development of the proposed method of network formalization and optimization of adaptive control of business planning processes is aimed at the development and creation of tools to support management decisions in various areas of business. An intelligent computer decision support system for optimizing the control of business planning processes, using the proposed method to solve such problems, can be developed, for example, using the technologies of expert systems and knowledge modeling based on production rules and / or neural networks, using elements of machine learning. The use of an intelligent computer system will allow a business entity to have at its disposal an effective toolkit for assessing the possibilities of implementing various business plans. 


\section{ACKNOWLEDGMENTS}

This work was supported by the Russian Basic Research Foundation, project no.18-01-00544 "Problems of attainability, control, estimation in dynamical systems with impulse control and uncertainty."

\section{REFERENCES}

1. C. Agulhari and M. Lacerda (2019). Observer-based state-feedback control design for LPV periodic discrete-time systems, European Journal of Control 49, 1-14, DOI: https: / / doi .org/10.1016/j . ej con.2019.02.002.

2. A. Astolfi, Nonlinear and Adaptive Control, Tools and Algorithms for the User (Imperial College Press, London, 2006) 313p.

3. M. Benosman (2018). Model-based vs data-driven adaptive control: an overview, International Journal of Adaptive Control and Signal Processing 32(5), 753-776, DOI: 10.1002 /acs . 2862.

4. L. Deng and Y. Chen (2017) Optimal control of uncertain systems with jump under optimistic value criterion, European Journal of Control, 38,7-15, DOI: https://doi.org/10.1016/j.ejcon.2017.06.002.

5. M. Huang, W. Gao, and Z.P. Jiang (2019). Connected cruise control with delayed feedback and disturbance: an adaptive dynamic programming approach, International Journal of Adaptive Control and Signal Processing 33(2), 356-370, DOI: https://doi.org/10.1002/acs.2834.

6. A. Kofman and G. Debazey, Network Planning Methods and Their Application. (ProgressPubl., Moscow, 1968) 182 p. [in Russian]

7. A. Takha Khemdi, Introduction to Operations Research, 7th edn (Vil'yams Publ., Moscow, 2005) 912p. [in Russian]

8. K.J. Astroem and B. Wittenmark, Adaptive Control, 2nd edn (Dover Publications, 2008), 590p.

9. K. Aksyonov, A. Antonova, and N. Goncharova (2018) "Choice of the scheduling technique taking into account the subcontracting optimization," in S.M. Thampi et al (eds) Advances in Signal Processing and Intelligent Recognition Systems, SIRS 2017, Advances in Intelligent Systems and Computing, Vol. 678 (Springer, Cham, 2017), pp. 297-304, DOI: https://doi.org/10.1007/978-3-319-67934-1_26.

10. A.F. Shorikov, Minimax Estimation and Control in Discrete Dynamical Systems. (Publ. Ural State University, Ekaterinburg, 1997), 242p.

11. A.F. Shorikov and E.V. Butsenko, Prediction and Optimization of the Results of Investment Projecting Control (Moscow, URSS-LENAND, Moscow, 2017), 272 p.

12. A.F. Shorikov, E.V. Butsenko, and V.G. Krylov (2016) Development of a computer expert system business planning, Journal of Applied Informatics (Moscow) 1.(5(65)), 8-18. 